\title{
STRATEGI PENGEMBANGAN USAHA TANI MELALUI PENERAPAN SNI 6729-2016 SEBAGAI UPAYA PENINGKATAN PENDAPATAN PETANI PADI ORGANIK
}

\author{
Mohammad Hoesain ${ }^{1}$, Sugeng Winarso ${ }^{2}$, Aryo Fajar Sunartomo ${ }^{3}$, dan Fariz Kustiawan Alfarisy ${ }^{4}$ \\ ${ }^{1}$ Proteksi Tanaman, Fakultas Pertanian, Universitas Jember \\ ${ }^{2}$ Ilmu Tanah, Fakultas Pertanian, Universitas Jember \\ ${ }^{3}$ Penyuluh Pertanian, Fakultas Pertanian, Universitas Jember \\ ${ }^{4}$ Pengelolaan Sumberdaya Alam dan Lingkungan, Pascasarjana, Universitas Jember \\ Email: piahoesain@yahoo.co.id
}

\begin{abstract}
ABSTRAK. Kendala yang dihadapi oleh Kelompok Tani Jaya II adalah pada bidang budidaya tanaman serta sediaan input organik. Tujuan dilakukan pengabdian ini adalah untuk membantu Kelompok Tani Jaya II dalam mengembangkan pertanian organik dan memproduksi input organik berupa pupuk organik cair dan pestisida organik. Pengabdian ini dilakukan di Desa Rowosari, Kecamatan Sumberjambe, Kabupaten Jember pada 13 Maret-31 Agustus 2019. Metode pelaksanaan yang dilakukan terdiri dari dua tahapan yaitu 1) pelatihan budidaya organik melalui focus group discussion (FGD), 2) pendampingan produksi pupuk organik cair dan pestisida organik. Hasil pengabdian kepada masyarakat yang diperoleh adalah petani mampu memahami budidaya secara organik mulai dari on farm hingga off farm. Petani telah mampu memproduksi pupuk organik cair dan pestisida organik masing-masing dengan volume 250 liter pada tahap 1. Selain itu petani mengetahui teknik aplikasi yang benar sesuai SNI 6729-2016. Harapan dari anggota Kelompok Tani Jaya II ke depan adalah untuk menambah produk organik yang lain yaitu hortikultura organik dan kopi organik.
\end{abstract}

Kata kunci: Pendapatan; Pengembangan; Organik; SNI; Strategi.

\section{STRATEGIES OF DEVELOPMENT OF FARMERS INCOME THROUGH IMPLEMENTATION SNI 6729-2016 AS EFFORT UPGRADING PROSPERITY OF PADDY ORGANIC}

\begin{abstract}
The problems on Tani Jaya II society are on farming aspects and supply input organic. The aim of this community engagement is the development of organic farming and produce input organics like liquid organic manure and organic pesticides. The engagement of society was conducted on March 13 to 31 August 2019 in Rowosari Village, Sub District of Sumberjambe, District of Jember. Methode on doing based two-steps 1) training organic farming through focus group discussion (FGD), 2) accompany producing liquid organic of manure and botanical pesticide. The result of engagement society is farmers can understand on-farm to off-farm. The farmer has been well to do produced liquid organic of manure and pesticide organic with 250 liters on the first session. In addition, farmers can know the application technique the right based SNI 6729-2016. Hoping from our farmer for the next chance, it will be to produce product organic another like horticulture organic and coffee organic.
\end{abstract}

Key words: Income; Development; Organic; SNI; Strategy.

\section{PENDAHULUAN}

Pangan merupakan salah satu dari isu permasalahan global dunia. Deklarasi PBB bahwa di tahun 2025 akan terjadi krisis dan kompetisi pangan yang terjadi hampir di beberapa negara termasuk Indonesia. Melalui sustainable development goals (SDGs) yang tertuang pada pilar ke 12 tentang produksi dan konsumsi berkelanjutan maka tantangan ke depan tidak hanya bagaiamana menghasilkan produksi pangan yang meningkat melainkan harus memperhatikan keamanan dan berwawasan lingkungan.

Pertanian organik merupakan kegiatan bercocok tanam dengan memperhatikan empat prinsip dasar yaitu kesehatan, ekologi, keadilan, dan perlindungan (Mayrowani,2012). Empat prinsip tersebut memberikan jaminan bahwa akan menghasilkan hubungan yang sinergi sehingga berdampak pada kebermanfaatan dalam bidang ekonomi, lingkungan, dan sosial. Pertanian organik adalah tantangan bagi Indonesia untuk mengahadapi kebutuhan dan ketersediaan dimasa mendatang. Untuk saat ini masyarakat mulai beralih kepada produk dari pertanian organik dengan alasan lebih sehat dan berkualitas.

Penggunaan pestisida saat ini tidak direkomendasikan dalam budidaya organik. Menurut (Mayrowani,2012) tidak memenuhi salah satu prinsip penting yaitu aspek perlindungan. Penggunaan pestisida sangat berbahaya baik terhadap kesehatan tubuh maupun lingkungan. Hasil penelitian dengan berdasarkan pajanan dari bahan aktif senyawa pestisida pada anggota bagian tubuh memberikan pengaruh yang signifikan terhadap gangguan kesehatan yang ditimbulkan (Pawukir dan Maryono, 2002)(Yuantari et al., 2015). Oleh sebab itu penggunaan pestisida harus disertai oleh alat pelindung diri agar terlindungi dari pajanan bahan aktif senyawa pestisida. 
Perkembangan budidaya organik di Indoensia semakin tahun semakin meningkat. Berdasarkan hasil laporan Statistik Pertanian Organik Indonesia pada tahun 2014 bahwa pada tahun 2008 - 2010 luas lahan organik mampu mencapai 103908,9 hektar namun pada tahun 2011-2014 terjadi penurunan menjadi 67426,57 hektar (Imani et al., 2018). Ada beberapa faktor yang menyebabkan penurunan luas lahan organik mulai dari keinginan petani yang ingin mendapatkan produksi yang tinggi, pertumbuhan tanaman lebih lambat, serta nilai ekonomi yang diperoleh tidak sebanding dengan yang diperoleh.

Terkait pertanian organik pemerintah telah melakukan revisi dengan SNI 6729-2013 dirubah dengan ketentuan terbaru yang diatur dalam SNI 6729-2016 bahwa pangan organik merupakan bahan yang berasal dari lahan kemudian menerapkan kegiatan-kegiatan berbasis lingkungan dengan tujuan menjaga kesetimbangan lingkungan, upaya proteksi tanaman, serta pengelolaan sumberdaya alam yang berkelanjutan (Dermiyati, 2015). SNI 6729-2016 telah menetapkan standar kriteria penggolongan produk organik mulai dari persyaratan pertanian organik, penanganan organik (pengangkutan, penyimpanan, pengolahan, dan pengemasan).

Kelompok Tani Jaya II merupakan salah satu contoh kelompok tani pegiat organik yang terletak di Desa Rowosari, Kecamatan Sumberjambe, Kabupaten Jember. Kelompok Tani Jaya II telah memiliki sertifikat organik yang dikeluarkan oleh LeSOS (Lembaga Sertifikasi Organik Seloliman) Mojokerto dengan luasa lahan tanaman padi organik sebesar 15 hektar. Berdasarkan analisis kendala secara RRA (Rapid Rural Appraisal) kendala yang dihadapi selama bercocok tanam organik yaitu 1) proses budidaya yang terkadang masih menggunakan pupuk dan pestisida anorganik, 2) persediaan input teknologi pupuk organik dan pestisida organik, 3) serta manamejemen pemasaran produk.

Berdasarkan latar belakang di atas maka diperlukan inovasi teknologi sebagai upaya strategi pengembangan usaha tani pada Kelompok Tani Jaya II dengan menerapkan SNI 6729-2016 guna meningkatkan pendapatan dan kesejahteraan petani padi organik. Sehingga tujuan adanya program kemitraan masyarakat ini dapat membantu petani dalam menerapkan pertanian organik berpedoman pada SNI 6729-2016 sekaligus memberikan pendampingan berupa budidaya organik dan penguatan kelembagaan serta teknik pemasaran.

\section{METODE}

Pengabdian masyarakat dilaksanakan pada Kelompok Tani Jaya II di Desa Rowosari, Kecamatan Sumberjambe, Kabupaten Jember. Berdasarkan gambar 1 dapat dilihat bahwa Desa Rowosari dikelilingi oleh beberapa pegunungan sehingga dari faktor lingkungan dilengkapi oleh tanah subur dan air yang melimpah ruah.

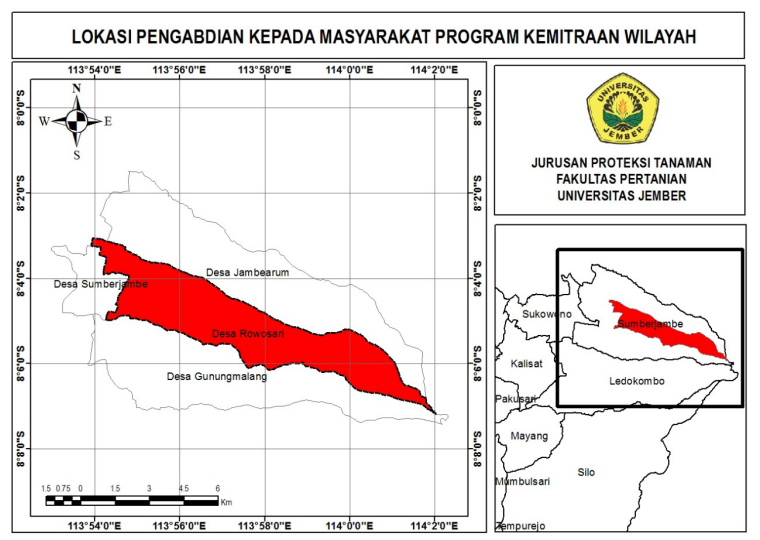

Gambar 1. Lokasi pengabdian masyarakat di Desa Rowosari.

\section{Focuss group discussion (FGD)}

Salah satu strategi untuk mengetahui berbagai kendala dan solusi yang bisa dilakukan dalam bertani padi organik yaitu melalui focuss group discussion (FGD). Pada pertemuan FGD tersebut dihadiri oleh pengurus yang terdiri dari ketua dan sekertaris Kelompok Tani Jaya II serta anggota kelompok tani yang berjumlah 30 petani. Pada pertemuan FGD tersebut terdiri dari dua bahasan pokok penting yaitu mengenai pelatihan budidaya padi organik serta standarisasi dalam bertani padi organik sesuai SNI 6729-2016 serta manajemen kelembagaan melalui penjelasan strategi model canvas.

\section{Standar operasional prosedur pembuatan pupuk organik cair dan pestisida organik}

Pemilihan bahan-bahan yang digunakan sebagai bahan pembuatan pupuk organik cair dan pestisida organik dikoleksi berdasarkan potensi spesifik wilayah. Bahan baku sesuai dengan spisifik wilayah akan memudahkan dalam mendapatkan bahan serta akan menjadi ciri khas dalam kombinasi antar beberapa bahan. Bahan-bahan yang telah dikoleksi telah melalui proses selektivitas bahan dan uji kompatibilitas berdasarkan literatur. Sehingga kegiatan pembuatan pupuk organik cair dan pestisida organik dapat dilihat pada tabel 1.

Tabel 1. Bahan-bahan yang digunakan untuk membuat pupuk organik cair dan pestisid organik

\begin{tabular}{cc}
\hline Bahan membuat pupuk organik & Bahan membuat pestisida organik \\
\hline Urin sapi 40 liter & Daun mimba \\
Sekam $30 \mathrm{~kg}$ & Daun mindi \\
Daun kacang-kacangan & Daun babadotan \\
Bonggol pisang & Daun pandan \\
Arang sekam & Daun kemangi \\
Gula merah & Daun jambu \\
Bakteri pengurai & Daun sirsak \\
Daun pait-paitan (Thitonia sp.) & Gula merah dan bakteri pengurai \\
Air secukupnya & Air secukupnya \\
\hline
\end{tabular}


Berdasarkan tabel 1 di atas untuk membuat pupuk organik cair dan pestisida organik adalah 1) menghaluskan semua bahan dengan menggunakan mesin pencacah, 2) bahan yang telah halus dicacah dimasukkan ke dalam tong fermentor, 3) ditambahkan air, EM4, urin sapi kemudian diaduk hingga homogen, 4) setelah bahan tercampur kemudian ditutup rapat dan difermentasi kurang lebih selama 2-3 minggu, 5) hasil fermentasi yang baik ditandai dengan aroma seperti tape, 6) panen pupuk organik cair dan pestisida organik menggunakan alat centrifuge, 7) hasil dari panen kemudian dimasukkan ke dalam botol ukuran volume satu liter untuk diberi label.

Pestisida nabati merupakan kebutuhan pokok yang harus dipenuhi dalam bertani organik. Tidak hanya pada tanaman pangan, tanaman perkebunan seperti kopi organik menjadi kebutuhan masyarakat. Pada Kelompok Tani Utami dan Koperasi Produsen Kopi Java Preanger sebagai usaha bagian dari penguatan kelembagaan juga dilakukan pelatihan pembuatan pestisida nabati dalam meningkatkan mutu kopi organik (Djuwendah, 2018). Keberhasilan dari sebuah kelompok tani diperngaruhi oleh seorang tokoh. Baik tokoh yang berpengaruh pada internal maupun eksternal kelembagaan tani. Kapasitas tokoh menentukan daya dukung keberhasilan program serta perencanaan kelembagaan tani (Darwis dan Zulfan, 2018).

\section{HASIL DAN PEMBAHASAN}

\section{Peningkatan kapasitas sumberdaya kelompok tani melalui Focus Group Discussion (FGD)}

Kelompok Tani Jaya II sampai saat ini telah menjadi sentra organik di Kabupaten Jember dan menjadi penyedia produk organik bagi Propinsi Jawa Timur dan beberapa kota yang membutuhkan produk organik. Melalui focus group discussion (FGD) petani diberikan pelatihan budidaya organik mengacu pada standar SNI 6729-2016. Pada sesi FGD dibagi menjadi dua topik bahasan yaitu bercocok tanam dan teknik pemasaran dengan manajemen kelembagaan kelompok tani. Hasil diskusi dengan pakar organik dengan anggota kelompok tani diinventarisasi kemudian dianalisis secara deskripsi. Adapun identitas dari Kelompok Tani Jaya II dapat dilihat pada tabel 2.
Tabel 2. Identitas kelompok Tani Jaya II Desa Rowosari, Sumberjambe, Jember.

\begin{tabular}{|c|c|c|}
\hline No & Identitas & Keterangan \\
\hline 1 & Nama Kelompok Tani & Kelompok Tani Jaya II \\
\hline 2 & Alamat & $\begin{array}{l}\text { Desa Rosowari, Kecamatan Sumber } \\
\text { jambe, Kabupaten Jember }\end{array}$ \\
\hline 3 & Struktur Kepengurusan & $\begin{array}{l}\text { Ketua : Rudiyanto } \\
\text { Sekertaris: Erna Heryati } \\
\text { Bendahara: Roni Ferdiyanto } \\
\text { Pengawas: Riski Hidayati }\end{array}$ \\
\hline 4 & Komoditas Organik & Padi \\
\hline 5 & Luas Lahan organik & 15 hektar \\
\hline 6 & Jumlah Anggota & 135 orang \\
\hline
\end{tabular}

Kelembagaan tani merupakan indikator bahwa usaha tani berjalan dengan baik. Adanya kelembagaan tani membantu mengkoordinir pengurus dan anggota serta keterlibatan para stakeholder untuk men-jalin kerja sama. Ada beberapa keuntungan yang diproleh dalam melakukan penguatan kelembagaan tani yaitu menurut (Rhamdani et al., 2015) adalah 1) dapat menciptakan suatu iklim yang kondusif dalam lingkup kelompok tani mulai dari pengurus hingga anggota, 2) dapat meningkatkan rasa percaya diri dan kreativitas anggota kelompok tani dalam meningkatkan peluang usaha tani, 3) serta memudahkan dalam melakukan koordinasi dalam mengidentifikasi kendala dan manajemen risiko dalam usaha tani yang di geluti. Hasil diskusi melaui FGD telah dirangkum dalam diagram alir pada tabel 3.

Berdasarkan hasil FGD tersebut petani sangat antusias untuk menjadikan pertanian di Kelompok Tani Jaya II maju. Terlihat dari keinginan petani untuk terus mengembangkan pertanian organik. Produk pangan organik yaitu padi organik telah tembus hingga ke luar Pulau Jawa. Adapun diversifikasi pangan organik yang dihasilkan adalah beras putih organik, beras merah organik, dan beras ketan organik.

\section{Pendampingan proses pembuatan pupuk organik dan pestisida organik}

Tim dari Universitas Jember memberikan pendampingan untuk memproduksi pupuk organik cair dan pestisida organik. Petani diberikan pelatihan serta praktek untuk membuat pupuk organik cair dan pestisida organik. Tujuan dari pelatihan ini adalah

Tabel 3. Hasil FGD Kelompok Tani Jaya II.

\begin{tabular}{|c|c|c|c|}
\hline No & Pendapat Petani & Solusi Dari Pakar & Tujuan Akhir \\
\hline 1 & $\begin{array}{l}\text { Petani saat ini telah mampu untuk } \\
\text { memproduksi padi organik, saat ini petani } \\
\text { ingin menambah sertifikasi organik pada } \\
\text { produk hortikultura. }\end{array}$ & $\begin{array}{l}\text { Menambah produk organik selain tanaman pangan } \\
\text { misalkan hortikultura juga mempunyai prospek } \\
\text { yang meng-untungkan. }\end{array}$ & Hortikultura organik \\
\hline 2 & $\begin{array}{l}\text { Jumlah limbah kotoran ayam melimpah, } \\
\text { petani ingin mengolah limbah ayam } \\
\text { sebagai pupuk organik. }\end{array}$ & $\begin{array}{l}\text { Limbah kotoran ayam selama pakan ayam berasal } \\
\text { dari konsentrat (kimia) tidak bisa diolah menjadi } \\
\text { pupuk organik }\end{array}$ & - \\
\hline $\begin{array}{l}\text { 3Petani selain memiliki } \\
\text { lahan padi organik, petani } \\
\text { juga mempunyai kebun } \\
\text { kopi dan berinisiatif untuk } \\
\text { go organic. }\end{array}$ & $\begin{array}{l}\text { Petani selain memiliki lahan padi } \\
\text { organik, petani juga mempunyai kebun } \\
\text { kopi dan berinisiatif untuk go organic. }\end{array}$ & $\begin{array}{l}\text { Kopi merupakan produk unggulan Kabupaten } \\
\text { Jember. Ketika Kelompok Tani Jaya II } \\
\text { berkeinginan menjadi go kopi organik, maka } \\
\text { tim akan mendukung dan mendampingi untuk } \\
\text { mengurus sertifikasi organik }\end{array}$ & $\begin{array}{l}\text { Kopi Organik Lereng } \\
\text { Raung dari Kelompok } \\
\text { Tani Jaya II }\end{array}$ \\
\hline
\end{tabular}


kelompok Tani Jaya II dapat membuat produksi masal secara mandiri untuk kebutuhan bercocok tanam pribadi. Tidak menutup kemungkinan produksi pupuk organik cair dan pestisida organik untuk dikomersilkan kepada anggota kelompok tani yang lain.

Selama proses pendampingan tim telah memfasilitasi untuk membuat tempat instalasi produksi proses pembuatan pupuk organik cair dan pestisida organik. Instalasi tersebut terdiri dai alat-alat mesin yaitu jenset, alat pencacah, dan centrifuge. Tong fermentor untuk proses fermentasi bahan serta rak botol untuk penyimpanan setelah panen. Pembuatan pupuk organik dan pestisida organik dilakukan proses fermentasi anaerob. Bahan-bahan yang telah dikoleksi dihaluskan dengan mesin pencacah. Kemudian dimasukkan ke dalam tong fermentor dan diberi larutan Em4 untuk mempercepat proses penguraian. Fermentasi dilakukan selama 2-3 minggu. Indiaktor keberhasilan ditandai dengan bau seperti tape. Untuk kelengkapan proses produksi dapat dilihat pada serangakaian gambar berikut ini.

Partisipasi anggota Kelompok Tani Jaya II berhasil memproduksi pupuk organik dan pestisida organik secara mandiri. Produksi pupuk organik cair dan pestisida organik digunakan oleh anggota kelompok tani untuk diaplikasikan ke lahan tanaman padi miliknya. Anggota kelompok tani juga diberikan wawasan untuk teknik aplikasi di lahan sawah mulai dari menentukan konsentrasi, volume semprot, serta volume larutan yang dibutuhkan. Kondisi sebelumnya anggota kelompok tani tidak pernah melakukan kalibrasi saat aplikasi di lahan pertanaman. Berdasarkan hasil pendampingan pembuatan pupuk organik cair dan pestisida organik dapat dilihat pada tabel 4 di bawah ini.

Tabel 4. Produksi pupuk organik cair dan pestisida organik Kelompok Tani Jaya II

\begin{tabular}{lcl}
\hline \multirow{2}{*}{\multicolumn{1}{c}{ Produksi }} & Tahap 1 & Tahap 2 \\
\cline { 2 - 3 } & Jumlah & Jumlah \\
\hline Pupuk organik cair & 250 liter & 500 liter \\
Pestisida organik & 250 liter & 500 liter \\
\hline
\end{tabular}

\section{SIMPULAN}

Kelompok Tani Jaya II mampu memproduksi masal pupuk organik cair dan pestisida organik secara mandiri dengan kapasitas volume masingmasing 250 liter. Kemudian kelompok tani juga telah mengetahui teknik kalibrasi dan aplikasi pupuk organik cair dan pestisida organik pada lahan padi organik. Harapan dari anggota Kelompok Tani Jaya II ke depan adalah untuk menambah produk organik yang lain yaitu hortikultura organik dan kopi organik.

\section{UCAPAN TERIMAKASIH}

Terimakasih disampaikan oleh Tim dari Universitas Jember kepada Direktorat Riset dan Pengabdian Kepada Masyarakat (DRPM) berdasarkan surat keputusan Nomor T/140/E3/RA.00/2019 dengan pendanaan hibah program kemitraan wilayah.

\section{DAFTAR PUSTAKA}

Darwis, R. S., dan I. Zulfan. 2018. Peningkatan Kapasitas Tokoh Masyarakat Desa Dalam Perencanaan Partisipatif Melalui Penerapan Nominal Group Technique (NGT). Dharmakarya, 7(4): 290-297.

Dermiyati. 2015 . Sistem Pertanian Organik Berkelanjutan. Yogyakarta : Plantaxia.

Djuwendah, E. 2018. Penguatan Kelembagaan Koperasi Produsen Kopi Java Preanger Dalam Upaya Meningkatkan Kinerja Bisnis dan Pendapatan Petani Kopi. Dharmakarya, 7(4): 228-233.

Imani, F., A. Charina, T. Karyani, and G. W. Mukti. 2018. Penerapan Sistem Pertanian Organik Di Kelompok Tani Mekar Tani Jaya Desa Cibodas Kabupaten Bandung Barat. Jurnal Pemikiran Masyarakat Ilmu Berwawasan Agribisnis, 4(2): 139-152.

Mayrowani, H. 2012. Pengembangan Pertanian Organik Di Indonesia; The Development Of Organic Agriculture In Indonesia. Forum Peneliti Agro Ekonomi, 30(2): 91-108.

Pawukir, E. S., dan J. Mariyono. 2002. Hubungan Antara Pengunaan Pestisida Dan Dampak Kesehatan Studi Kasus Di Dataran Tinggi Sumatar Barat. Manusia dan Lingkungan, 9(3): 126-136.

Ramdhani, H., S. A. Nulhaqim, and M. Fedryansyah. 2015. Peningkatan Kesejahteraan Petani Dengan Penguatan Kelompok Tani. Prosiding Peneliti dan Pengabdian Kepada Masyarakat, 2(3): 423-429.

Yuantari, M. G. C., B. Widianarko, and H. R. Sunoko. 2015. Analisis Risiko Pajanan Pestisida Terhadap Kesehatan Petani. Jurnal Kesehatan Masyarakat, 10(2): 239-244. 